\section{'Shadow sign' in congenital hypertrophy of the retinal pigment epithelium of young myopic pigmented patients}

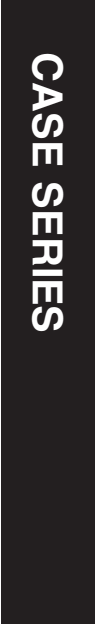

${ }^{1}$ Department of Ophthalmology, Stein Eye Institute, University of California, Los Angeles, CA, USA

${ }^{2}$ South Coast Retina Center, Long Beach, CA, USA

Correspondence: TA McCannel, Department of Ophthalmology, Stein Eye Institute, 100 Stein Plaza, University of California, Los Angeles, CA 90095, USA

Tel: +1 310206 7484;

Fax: +1 3107947904

E-mail: tmccannel@

jsei.ucla.edu

Received: 12 April 2015 Accepted in revised form: 25 August 2015

Published online:

16 October 2015

\begin{abstract}
Purpose Congenital hypertrophy of the retinal pigment epithelium (CHRPE) may simulate choroidal melanoma in certain cases. We report unique clinical features we have observed in cases of CHRPE in young myopic pigmented patients.

Methods Patients who were referred for evaluation of a suspicious choroidal lesion and found to have a CHRPE lesion with the clinical appearance of lesion elevation and a subretinal fluid-like 'shadow sign' were included. Patient and lesion characteristics were tabulated. Available images, including fundus photography, ultrasonography, optical coherence tomography (OCT), and fluorescein angiography (FA) were reviewed.

Results Six patients were included. The 'shadow sign' was anterior to the CHRPE lesion in all cases. The mean age of the patients was 27.3 years. The ethnicities of the patients were Chinese $(n=1)$, Hispanic $(n=3)$, or African-American $(n=2)$. Five of six patients were myopic. Conclusions Although most CHRPE lesions appear flat on ophthalmoscopy, lesions in young myopic patients of pigmented ethnicities may appear elevated with a 'shadow sign' due to 'dark without pressure.' This new finding may be related to the vitreoretinal interface in young myopic pigmented patients and must be distinguished from true subretinal fluid and lesion thickness, which are often observed in choroidal melanoma.

Eye (2016) 30, 160-163; doi:10.1038/eye.2015.187; published online 16 October 2015
\end{abstract}

\section{Introduction}

Congenital hypertrophy of the retinal pigment epithelium (CHRPE) is a benign disorder of the
MY Chang ${ }^{1}$, JB McBeath², CA McCannel ${ }^{1}$ and TA McCannel ${ }^{1}$ retinal pigment epithelium (RPE) classically described as flat, well-delineated, and with depigmented lacunae developing over time. ${ }^{1,2}$ We describe six cases in which a 'shadow sign' simulated subretinal fluid and lesion elevation, giving the false impression of a malignant process.

Materials and methods

Patients who were referred for evaluation of a suspicious choroidal lesion and found to have a CHRPE lesion with the clinical appearance of lesion elevation and a subretinal fluid-like 'shadow sign' were included. Patients' age, sex, race, refraction, and lesion characteristics were tabulated. Imaging studies, including fundus photography, ultrasonography, optical coherence tomography (OCT), and fluorescein angiography (FA), were reviewed when available.

\section{Results}

Six patients were identified who were referred for evaluation of a suspicious choroidal lesion and were found to have CHRPE with an associated 'shadow sign' (Table 1). The mean age of the patients was 27.3 years (range $12-41$ years). The ethnicities of the patients were Chinese $(n=1)$, Hispanic $(n=3)$ or African-American $(n=2)$. Five of six patients were myopic (range -1.00 to -5.00 diopters, spherical equivalent).

Color fundus photographs of patients one through three are shown in Figures 1-3. Ultra wide-field fundus photography was used in Patient 1, but standard color photography was used on the other five patients. In all six cases, the 'shadow' was located anteriorly, simulating the appearance of subretinal fluid. In three cases, the shadow created the appearance of lesion elevation. However, ultrasonography and 
Table 1 Patient and lesion characteristics of six eyes with congenital hypertrophy of the retinal pigment epithelium (CHRPE) associated with a subretinal fluid-like 'shadow sign'

\begin{tabular}{|c|c|c|c|c|c|}
\hline $\begin{array}{l}\text { Patient } \\
\text { number }\end{array}$ & Age (years) & Sex & Race & Refraction & Lesion characteristics \\
\hline 1 & 41 & F & Hispanic & $\begin{array}{r}-1.00+0.75 \times 135 \\
-1.25+2.50 \times 33\end{array}$ & $\begin{array}{l}\text { Flat appearing uniformly pigmented lesion with a well-demarcated } \\
\text { shadow anteriorly }\end{array}$ \\
\hline 2 & 20 & M & African-American & $\begin{array}{l}-1.25-0.50 \times 125 \\
-1.00-0.50 \times 15\end{array}$ & $\begin{array}{l}\text { Flat appearing uniformly pigmented small lesion with a well- } \\
\text { demarcated shadow anteriorly }\end{array}$ \\
\hline 3 & 41 & F & Hispanic & $\begin{array}{l}-4.00-0.75 \times 145 \\
-4.25-0.25 \times 15\end{array}$ & $\begin{array}{l}\text { Flat appearing uniformly pigmented small lesion with a well- } \\
\text { demarcated shadow anteriorly }\end{array}$ \\
\hline 4 & 19 & M & Chinese & $\begin{array}{l}-5.00 \mathrm{sph} \\
-5.00 \mathrm{sph}\end{array}$ & $\begin{array}{l}\text { Elevated appearing uniformly pigmented lesion with a well-demarcated } \\
\text { area of shadow anteriorly, with disappearance after } 3 \text { years }\end{array}$ \\
\hline 5 & 12 & F & African-American & $\begin{array}{c}-5.75 \\
+4.00 \times 100 \\
-5.75+4.00 \times 82\end{array}$ & $\begin{array}{l}\text { Elevated appearing uniformly pigmented lesion with a well-demarcated } \\
\text { shadow anteriorly, with reduction in extent over } 3 \text { years }\end{array}$ \\
\hline 6 & 31 & F & Hispanic & $\begin{array}{l}-2.25 \mathrm{sph} \\
-2.25 \mathrm{sph}\end{array}$ & $\begin{array}{l}\text { Elevated appearing pigmented lesion with a well-demarcated shadow } \\
\text { anteriorly, with disappearance after } 3 \text { years }\end{array}$ \\
\hline
\end{tabular}

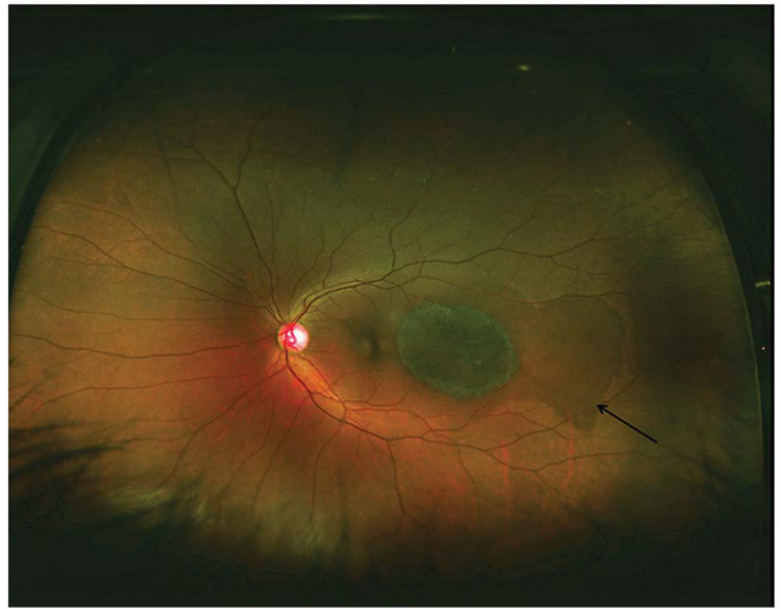

Figure 1 Ultra wide-field color fundus photograph of a 41-yearold Hispanic female demonstrating a well-demarcated 'shadow sign' anterior to a CHRPE lesion (arrow).

OCT in all cases confirmed that the lesions were flat with no associated subretinal fluid. In addition, OCT demonstrated outer retinal atrophy with loss of the ellipsoid and interdigitation zones in the area of the CHRPE lesion (Figure 2b). In the area of the 'shadow,' OCT showed hyporeflectivity of these same layers. Fluorescein angiography demonstrated blocking of the CHRPE lesion, whereas the 'shadow' was indistinguishable from the surrounding retina (Figure 2c).

In three patients, follow-up over 3 years demonstrated reduction or disappearance of the 'shadow sign.'

\section{Discussion}

We describe for the first time a 'shadow sign' associated with CHRPE lesions in young, myopic patients with hyperpigmentation of the fundus associated with race. Although the shadow may simulate the presence of subretinal fluid or lesion elevation on clinical examination, ultrasonography, and optical coherence tomography (OCT) confirm that the lesion is flat and there is no fluid present.

The appearance of the 'shadow' matches the description for 'dark without pressure' first published by Nagpal et al, ${ }^{3}$ as 'homogeneous, geographical, flat, brown areas.' Fawzi et al ${ }^{4}$ reported that the OCT characteristics of these 'dark without pressure' lesions consist of hyporeflectivity of photoreceptor zones, consistent with the OCT findings in our cases. As in our study, no vitreoretinal alterations were found on OCT, although the authors acknowledge the possibility that the changes may have been precipitated by vitreous traction. The cause of the related phenomenon of 'white without pressure' has been traditionally attributed to vitreoretinal alteration based on histopathological studies. ${ }^{5}$

The reason for the association of CHRPE lesions with 'dark without pressure' in our patients is unclear. CHRPE lesions have been found to be associated with 'white without pressure' in $1 \%$ of cases, ${ }^{1}$ and it is possible that they may cause vitreoretinal interface alterations leading to the either 'dark without pressure' or 'white without pressure' based on fundus pigmentation. In a series of 10 patients with 'white' or 'dark without pressure,' 6 of 7 patients with 'dark without pressure' were of pigmented race, whereas 2 of 3 patients with 'white without pressure' were Caucasian. ${ }^{4}$ In our series, all patients were of pigmented race with hyperpigmented fundi, and this may have led to the appearance of 'dark without pressure' rather than 'white without pressure.'

In Cases 4-6, longer follow-up revealed a decrease in the shadow sign, which may be related to the theoretical breakdown of the vitreous with age reducing the 
a

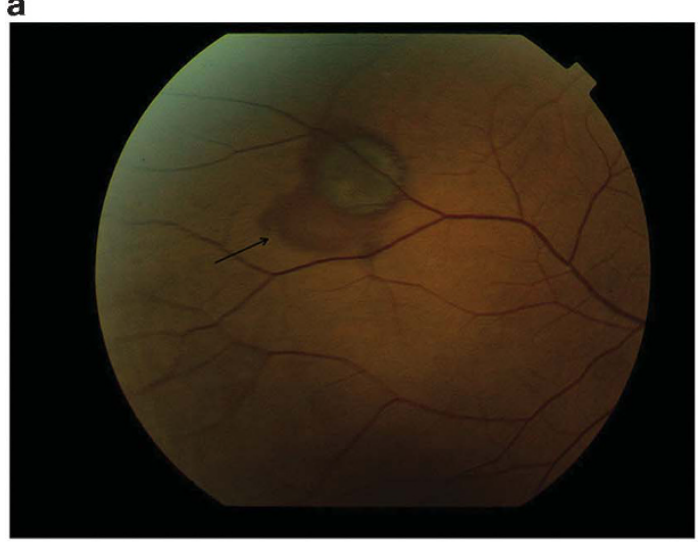

b
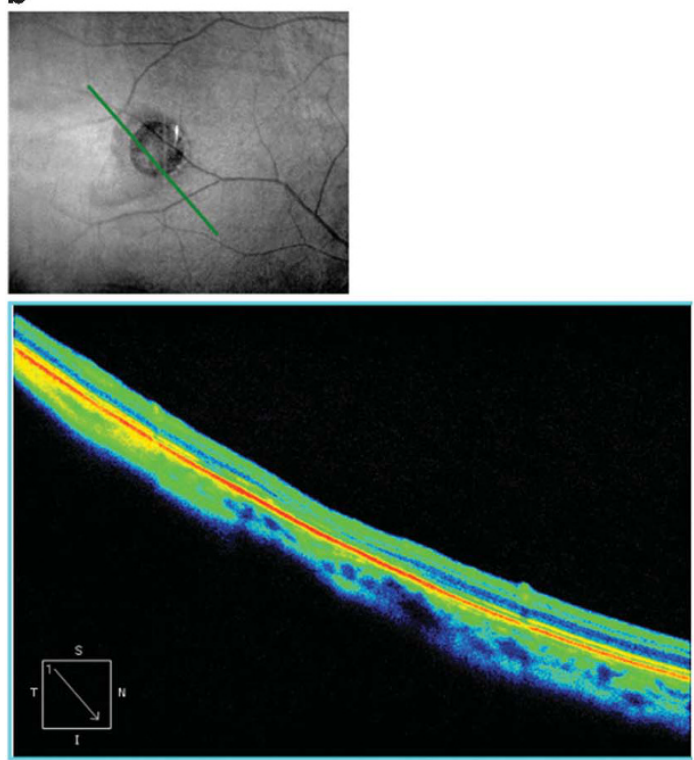

C

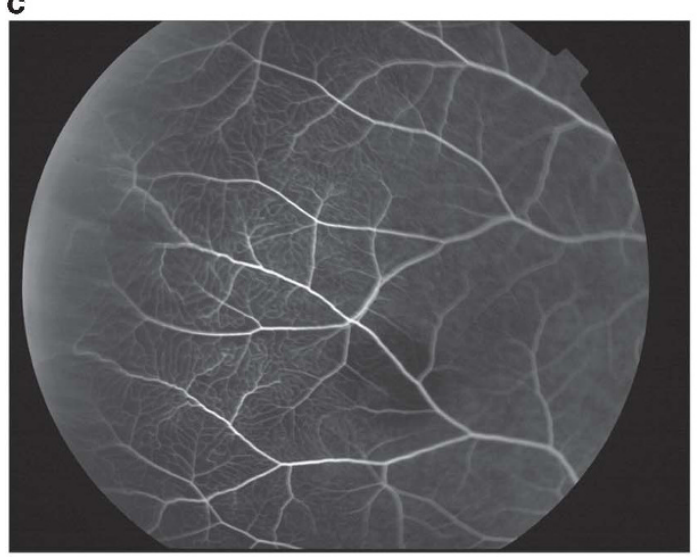

Figure 2 (a) Color fundus photograph of a 20-year-old myopic African-American male demonstrating the 'shadow sign' anterior to a CHRPE lesion (arrow). (b) Optical coherence tomography demonstrates outer retinal atrophy in the area of the CHRPE lesion, with hyporeflectivity of the ellipsoid and interdigitation layers in the adjacent area corresponding to the 'shadow.' (c) Fluorescein angiography reveals blocking of the CHRPE lesion. The 'shadow' is indistinguishable from the surrounding retina.

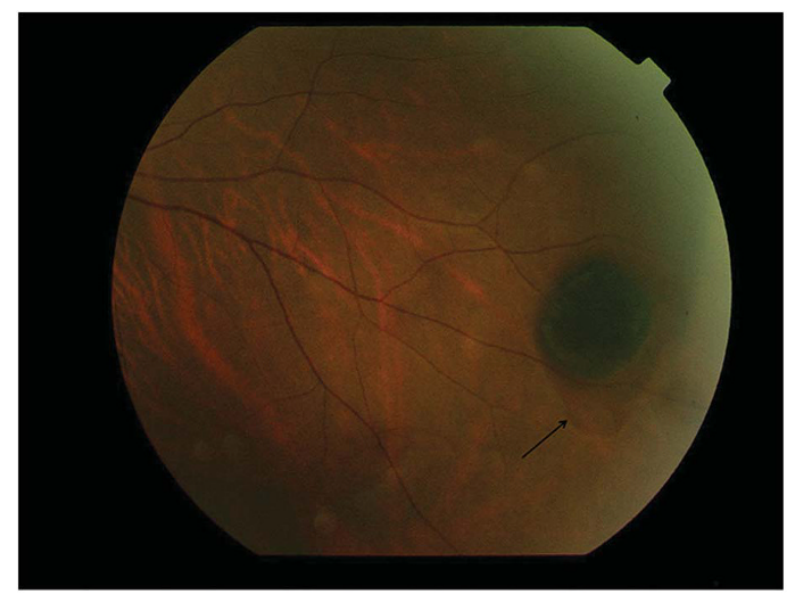

Figure 3 Color fundus photograph of a 41-year-old myopic Hispanic female demonstrating the 'shadow sign' anterior to a CHRPE lesion (arrow).

prominence of the vitreoretinal interface. The fact that we do not see this shadow in older patients may attest to this.

Finally, myopia was also a common denominator in five of the six patients presented, and vitreoretinal interface alterations influenced by myopia are well described. ${ }^{6-8}$

In summary, we report the 'shadow sign' with CHRPE lesions in young, myopic, pigmented patients, which may simulate the clinical appearance of subretinal fluid and/ or lesion thickness. Clinicians must be aware that this sign may cause a benign process to appear malignant on ophthalmoscopy, and we recommend the use of ancillary testing as appropriate to rule out the possibility of choroidal melanoma.

\section{Summary}

What was known before

- Congenital hypertrophy of the retinal pigment epithelium (CHRPE) is a benign disorder of the retinal pigment epithelium (RPE) classically described as flat, welldelineated, and with depigmented lacunae developing over time. On clinical examination, it is important to differentiate this benign lesion from a malignant process, such as choroidal melanoma.

\section{What this study adds}

- We report the 'shadow sign' with CHRPE lesions in young, myopic, pigmented patients, which may simulate the clinical appearance of subretinal fluid and/or lesion thickness. The appearance of the 'shadow sign' corresponds to the phenomenon of 'dark without pressure,' which may be related to vitreoretinal interface alterations in these patients. Clinicians should be aware that this sign may cause a benign CHRPE lesion to simulate choroidal malignant melanoma on ophthalmoscopy, and should order ancillary testing as appropriate. 


\section{Conflict of interest}

The authors declare no conflict of interest.

\section{Acknowledgements}

This work was supported by an unrestricted grant from Research to Prevent Blindness and the George E. and Ruth Moss Trust.

\section{References}

1 Shields CL, Mashayekhi A, Ho T, Cater J, Shields JA. Solitary congenital hypertrophy of the retinal pigment epithelium: clinical features and frequency of enlargement in 330 patients. Ophthalmology 2003; 110(10): 1968-1976.

2 Buettner H. Congenital hypertrophy of the retinal pigment epithelium. Am J Ophthalmol 1975; 79(2): 177-189.
3 Nagpal KC, Goldberg MF, Asdourian G, Goldbaum M, Huamonte F. Dark-without-pressure fundus lesions. Br J Ophthalmol 1975; 59(9): 476-479.

4 Fawzi AA, Nielsen JS, Mateo-Montoya A, Somkijrungroj T, $\mathrm{Li} \mathrm{HK}$, Gonzales J et al. Multimodal imaging of white and dark without pressure fundus lesions. Retina 2014; 34(12): 2376-2387.

5 Watzke RC. The ophtalmoscopic sign 'white with pressure'. A clinicopathologic correlation. Arch Ophthalmol 1961; 66: 812-823.

6 Itakura H, Kishi S, Li D, Nitta K, Akiyama H. Vitreous changes in high myopia observed by swept-source optical coherence tomography. Invest Ophthalmol Vis Sci 2014; 55(3): 1447-1452.

7 Akiba J. Prevalence of posterior vitreous detachment in high myopia. Ophthalmology 1993; 100(9): 1384-1388.

8 Morita H, Funata M, Tokoro T. A clinical study of the development of posterior vitreous detachment in high myopia. Retina 1995; 15(2): 117-124. 